\title{
The investigation of meteorite stream using the Chinese historical records
}

\author{
I-Ching Yang*
}

Department of Applied Science, National Taitung University, Taitung County, Taiwan

\section{Article history: \\ Received 28 January 2021 \\ Revised 22 September 2021 \\ Accepted 25 September 2021}

Keywords:

Meteorite stream, Moving average,

Chinese historical records of meteorite

Citation:

Yang, I.-C., 2021: The investigation of meteorite stream using the Chinese historical records. Terr. Atmos. Ocean. Sci., 32, 561-569, doi: 10.3319/

TAO.2021.09.25.01

\begin{abstract}
A meteorite cataloguing, gathering report, based on Chinese historical records of "Song Shi", "Yuan Shi”, and "Ming Shi" was constructed, which consists of 52 meteorites appearing between the years 960 A.D. to 1644 A.D. Several peaks over $1 \sigma$ level are found in the bar chart of meteorites with their moving average and emerge from February to July, which also has a good agreement with the window of the moving average of meteors. Therefore, the agreement suggests that the appearance of a meteorite stream could be found in astronomical records of the historical books in China.
\end{abstract}

\section{INTRODUCTION}

At the night sky, one has probably seen a streak of light in a fraction of a second and quickly fades. The small, solid body while in space and before it reaches the atmosphere, is called a meteoroid. When a meteoroid enters our atmosphere and heats up, the trail of luminous gas it leaves is called a meteor. When the body lands on the ground, it is called a meteorite (Arny and Schneider 2014). When the apparent brightness of the meteor reaches a magnitude around -14 or brighter, it is generally called a fireball (Di Martino and Cellino 2004). Meteorites and fireballs are interesting natural events all the time, which could have a significant influence on human civilization as well (Beech 2002). Generally, meteorites and fireballs originate from meteoroids which are the fragments of comets or asteroids spread in outer space. The meteoroid streams, which are ejected from the parent body, are organized with orbits similar to their parent (Hughes and McBride 1989). They are perturbed by radiation pressure from Sun, the Poynting-Robertson effect, and the Yarkovsky effect (Brown 1999), and by the planets, in particular Jupiter (McNaught and Asher 1999). Every time the Earth passes through a meteor stream, it will be seen that meteors appear to come from the same general

\footnotetext{
* Corresponding author

E-mail: icyang@nttu.edu.tw
}

direction in the sky. Meteors of this type are part of what is called a meteor shower (Arny and Schneider 2014). As Leonids and Geminids, these two famous meteor showers are caused by the meteoroid stream from comet 55P/TempelTuttle (Yeomans 1981) and asteroid 3200 Phaethon (Williams and $\mathrm{Wu}$ 1993). Because of the diversity of source and the size spectrum of meteoroid streams, they would bring meteor streams (Southworth and Hawkins 1963), fireball streams (Terentjeva 1990), and meteorite streams (Jones and Williams 2008) as Earth encounters.

In earlier studies, scientists (Southworth and Hawkins 1963) tried to recognize meteor stream, its orbital formation, its orbital evolution, and its parent bodies that associate with the meteor shower, such as Quadrantid (Williams et al. 1979; McIntosh 1990), Perseid (Lindblad and Porubčan 1994; Brown and Jones 1998), Draconid (Beech 1986; Wu and Williams 1995), Geminid (Plavec 1950; Fox et al. 1982; Williams and Wu 1993), Leonid (Yeomans 1981; Brown and Jones 1993; Asher 1999), Orionid and Eta Aquarid (Hajduk 1970; McIntosh and Hajduk 1983; Hughes 1988), Taurid (Jones 1986; Steel et al. 1991), and Giacobinid (Davies and Lovell 1955; Davies and Turski 1961). According to these studying, the existence of the meteor streams associated with meteor showers is confirmed. The meteor stream implies that all have similar heliocentric 
orbits, whose orbital elements can be determined, and this can give a strong indication of its parentage (Jopek and Williams 2013). Hence, the observation of a large number of fireballs or meteorites also will give the orbital and structural features of fireball or meteorite streams if they existed.

Existences of the fireball streams have been established and investigated (Terentjeva 1990; Porubčan and Gavajdová 1994). Some researches indicated that the association between fireball streams and asteroids (Gavajdová 1995; Porubčan et al. 2004) or cometoids (or comet like asteroids) (Terentjeva and Barabanov 2002). In contrast to meteor streams and fireball streams, there is a little literature (Spurný et al. 2003) to discuss meteorite streams, because of rare meteorite events. For some reason, a gap appears around the meteorite category from the historical records. Many historical records of various civilizations have been documenting meteorites for a long period of time. For instance, several types of research are worked on fireball cataloguing, gathering reports for the period of the last century (Denning 1912; Baggaley 1977; Terentjeva 1990; Beech 2006), or of these ten centuries (Astapovič and Terenteva 1968; Zamora et al. 2015), and the properties of fireball streams are studying through those efforts. By contrast, in each dynasty of ancient China, the official astronomical observation agency would be established. The official astronomical observation agency recorded and kept the celestial phenomena, which will be included in the history books. To find the possible existence of meteorite streams, the astronomical records in the historical books of "Song Shi" (960 A.D. - 1279 A.D.) (TuoTuo 1977), "Yuan Shi" (1271 A.D. - 1368 A.D.) (Song 1976), and "Ming Shi" (1368 A.D. - 1644 A.D.) (Zhang 1974) in China are catalogued, gathered, and analyzed.

\section{METEORITE CATALOGUING AND COMPUTTIONAL ANALYSIS}

The official historical record for China is named as the Twenty-Four Histories, which are the Chinese historical books covering a period from $3000 \mathrm{BC}$ to the Ming dynasty in the 17th century. These Chinese historical books include many official records of meteorites. The reason why "Song Shi", "Yuan Shi", and "Ming Shi" were selected is that they are the last three historical books of the Twenty-Four Histories edited by the government. These historical books are introduced in Table 1. The draft history of Qing, also named "Qing Shi Gao", is a draft of the official history of the Qing dynasty, which was quickly published in 1928. Owing to many factual or superficial errors "Qing Shi Gao" will not be taken into consideration. Generally, the official astronomical observation agency is named "Taishiju" in the Sony dynasty, "Taishiyuan" in the Yuan dynasty, and "QinTianjian" in the Ming dynasty, and recorded the celestial phenomena including meteorites. These meteorite records in the historical books contain the date and location of the occurrence, as well as the description of the occurrence process and the appearance of the meteorite. For example, the meteorite's historical record of "Song Shi" in 1235 A.D., a meteorite falls in Jintang, Huai' an (Chengdu, Sichuan now) with sound like thunder and becomes red gravel. However, most of these historical records contain date, but not accurate moment.

Since the meteorite records use the sexagenary of the Chinese calendar for time-keeping, it needs to be converted into a Gregorian calendar. Here a meteorite cataloguing (shown in Table 2), gathering report based on "Song Shi", "Yuan Shi", and "Ming Shi" was constructed, which

Table 1. The Introduction of historical books in this study.

\begin{tabular}{|c|c|c|}
\hline $\begin{array}{c}\text { Name of } \\
\text { historical } \\
\text { book }\end{array}$ & History of dynasty & Publication process \\
\hline "Song Shi” & $\begin{array}{l}\text { Starting in 960, the first year of } \\
\text { Emperor Taizu of Song's Jianlong Era, } \\
\text { and ended in 1276, the second year of } \\
\text { Emperor Gong of Song's Deyou Era. }\end{array}$ & $\begin{array}{l}\text { Through the Yuan dynasty's initial epoch, Kublai, the founding emperor commanded his follow- } \\
\text { ers to compile the history of the Song Dynasty. However, as a result of the style dispute, he didn't } \\
\text { finish it during his tenure. Then in the March of 1343, the third year of Emperor Huizong's reign, } \\
\text { under the order of that emperor, the courtiers started to edit the Song Shi, the history of the Song } \\
\text { Dynasty. Only after two and a half years, in the October of } 1345 \text {, they completed this task. }\end{array}$ \\
\hline "Yuan Shi”" & $\begin{array}{l}\text { Starting in 1271, the eighth year of } \\
\text { Emperor Shizu of Yuan's Zhiyuan Era, } \\
\text { and ended in 1368, the twenty-eighth } \\
\text { year of Emperor Huizong of Yuan's } \\
\text { Zhizheng Era. }\end{array}$ & $\begin{array}{l}\text { Yuan Shi, the recording of the Yuan Dynasty, was originally written under the command of } \\
\text { Ming's founding emperor Yuanzhang Zhu in 1369. Then in 1370, it was the Míng dynasty's of- } \\
\text { ficial historical institute guided by Song Lian which really complied with the content. Unfortu- } \\
\text { nately, the courtiers found that they couldn't gain enough materials of Yuan's later period, they } \\
\text { had to stop editing for a while and search for more historical data. In the same year, with more } \\
\text { data, they successfully finished Yuan Shi in a second compilation. It merely took courtiers } 331 \\
\text { days to complete the } 210 \text { chapters. }\end{array}$ \\
\hline "Ming Shi" & $\begin{array}{l}\text { Starting in 1368, the first year of } \\
\text { Emperor Taizu of Ming's Hongwu Era, } \\
\text { and is ended in 1644, the seventeenth } \\
\text { year of Emperor Sizong of Ming's } \\
\text { Chongzhen Era. }\end{array}$ & $\begin{array}{l}\text { It was made up of } 332 \text { rolls, compiled by the Qing Dynasty's courtiers who were under the lead- } \\
\text { ership of Zhang Tingyu. From the second year of Emperor Shunzhi to the fourth year of Emperor } \\
\text { Qianlong, it took nearly one century to finish Ming Shi. Actually, the essential sections were } \\
\text { completed in Kangxi's Era. }\end{array}$ \\
\hline
\end{tabular}


Table 2. A meteorite cataloguing, gathering report based on "Song Shi", "Yuan Shi”, and "Ming Shi”, have 52 meteorites between the years 960 A.D. to 1644 A.D.

\begin{tabular}{|c|c|c|c|c|c|}
\hline \multicolumn{2}{|c|}{ Gregorian calendar } & \multicolumn{4}{|c|}{ Chinese calendar } \\
\hline Year & day of year & dynasty & year & the month of the lunar year & Date in sexagenary \\
\hline 1137 & 242 & \multirow{3}{*}{ Song } & the seventh year of the Shaoxing's Era & the eighth month & Ren-Yin \\
\hline 1189 & 89 & & the sixteenth year of the Chunxi's Era & the third month & Ren-Yin \\
\hline 1196 & 201 & & the second year of the Qingyuan's Era & the sixth month & Xin-Wei \\
\hline 1298 & 184 & \multirow{5}{*}{ Yuan } & the second year of the Dade's Era & the fifth month & Ji-You \\
\hline 1350 & 56 & & the tenth year of the Zhizheng's Era & the first month & $\mathrm{Jia}-\mathrm{Xu}$ \\
\hline 1356 & 298 & & the sixteenth year of the Zhizheng's Era & the tenth month & Ding-Wei \\
\hline 1359 & 144 & & the nineteenth year of the Zhizheng's Era & the fourth month & Ji-Chou \\
\hline 1363 & 204 & & the twenty-third year of the Zhizheng's Era & the sixth month & Geng-Xu \\
\hline 1427 & 7 & \multirow{41}{*}{ Ming } & the first year of the Xuande's Era & the twelfth month & $\mathrm{Ji}-\mathrm{Si}$ \\
\hline 1470 & 204 & & the sixth year of the Chenghua's Era & the sixth month & Ren-Shen \\
\hline 1476 & 346 & & the twelfth year of the Chenghua's Era & the eleventh month & Yi-Chou \\
\hline 1478 & 201 & & the fourteenth year of the Chenghua's Era & the sixth month & Xin-Hai \\
\hline 1484 & 155 & & the twentieth year of the Chenghua's Era & the fifth month & Bing-Shen \\
\hline 1487 & 145 & & the twenty-third year of the Chenghua's Era & the fifth month & Ren-Yin \\
\hline 1491 & 319 & & the fourth year of the Hongji's Era & the tenth month & Ding-Si \\
\hline 1497 & 42 & & the tenth year of the Hongji's Era & the first month & Ren-Zi \\
\hline 1497 & 86 & & the tenth year of the Hongji's Era & the second month & Bing-Shen \\
\hline 1497 & 275 & & the tenth year of the Hongji's Era & the ninth month & $\mathrm{Yi}-\mathrm{Si}$ \\
\hline 1498 & 48 & & the eleventh year of the Hongji's Era & the first month & Gui-Hai \\
\hline 1499 & 178 & & the twelfth year of the Hongji's Era & the fifth month & Wu-Yin \\
\hline 1501 & 230 & & the fourteenth year of the Hongji's Era & the leap seventh month & $\mathrm{Xin}-\mathrm{Si}$ \\
\hline 1506 & 245 & & the first year of the Zhengde's Era & the eighth month & Ren-Xu \\
\hline 1507 & 8 & & the first year of the Zhengde's Era & the twelfth month & Geng-Wu \\
\hline 1511 & 260 & & the sixth year of the Zhengde's Era & the eighth month & Gui-Mao \\
\hline 1514 & 160 & & the ninth year of the Zhengde's Era & the fifth month & Ji-Mao \\
\hline 1518 & 59 & & the thirteenth year of the Zhengde's Era & the first month & Ji-Wei \\
\hline 1520 & 38 & & the fifteenth year of the Zhengde's Era & the first month & Ding-Wei \\
\hline 1533 & 148 & & the twelfth year of the Jiajing's Era & the fifth month & Ding-Wei \\
\hline 1540 & 166 & & the nineteenth year of the Jiajing's Era & the fifth month & Xin-Chou \\
\hline 1563 & 107 & & the forty-second year of the Jiajing's Era & the third month & Gui-Mao \\
\hline 1568 & 97 & & the second year of the Longqing's Era & the third month & Ji-Wei \\
\hline 1575 & 183 & & the third year of the Wanli's Era & the fifth month & Gui-Hai \\
\hline 1576 & 330 & & the fourth year of the Wanli's Era & the eleventh month & Jia-Wu \\
\hline 1585 & 219 & & the thirteenth year of the Wanli's Era & the seventh month & Xin-Si \\
\hline 1587 & 194 & & the fifteenth year of the Wanli's Era & the sixth month & Bing-Yin \\
\hline 1587 & 195 & & the fifteenth year of the Wanli's Era & the sixth month & Ding-Mao \\
\hline 1589 & 57 & & the seventeenth year of the Wanli's Era & the first month & Geng-Shen \\
\hline 1589 & 295 & & the seventeenth year of the Wanli's Era & the ninth month & $\mathrm{Wu}-\mathrm{Wu}$ \\
\hline 1591 & 168 & & the nineteenth year of the Wanli's Era & the fourth month & Xin-You \\
\hline 1594 & 87 & & the twenty-second year of the Wanli's Era & the second month & Bing-Chen \\
\hline 1599 & 105 & & the twenty-seventh year of the Wanli's Era & the third month & Geng-Zi \\
\hline 1605 & 301 & & the thirty-third year of the Wanli's Era & the ninth month & $\mathrm{Wu}-\mathrm{Zi}$ \\
\hline 1605 & 302 & & the thirty-third year of the Wanli's Era & the ninth month & Ji-Chou \\
\hline 1607 & 356 & & the thirty-fifth year of the Wanli's Era & the eleventh month & Gui-Si \\
\hline 1615 & 89 & & the forty-third year of the Wanli's Era & the third month & Wu-Shen \\
\hline 1618 & 326 & & the forty-sixth year of the Wanli's Era & the tenth month & Xin-You \\
\hline 1623 & 293 & & the third year of the Tianqi's Era & the ninth month & Jia-Yin \\
\hline 1630 & 111 & & the third year of Chongzhen's Era & the third month & Ji-Chou \\
\hline 1636 & 278 & & the ninth year of Chongzhen's Era & the ninth month & Ding-Wei \\
\hline
\end{tabular}


consists of 52 meteorites between the years 960 A.D. to 1644 A.D. The bar chart for the situation of the annual rates is plotted in Fig. 1a. To inspect the meteorite streams, the graph of meteorites for the 960 A.D. - 1644 A.D. period with its moving average (black line) is shown in Fig. 1b. Using the method of moving average (Wold 1949), the average value $f(x)$ is obtained as

$f(x)=\frac{1}{2 n+1} \sum_{k=x-n}^{x+n} p_{k}$

where $p_{k}$ is the count number of events and $n=15$, and the window is about one month. Furthermore, the data ranges from 960 A.D. to 1644 A.D., covering about 700 years. Considering the earth's precession period about 26000 years into account, a 10 degree or 10 days of axial precession exists. To choose a one-month window will avoid the problem of axial precession and no accurate momentum. Ultimately the relation to an average value of meteorite events and date is brought out. In Fig. 1b, the blue line is the average daily occurrence frequency. Then, the red and green lines are $1 \sigma$ and $2 \sigma$ levels. So, there are eight peaks over $1 \sigma$ level. One of these eight peaks, which is about days $189-193$, is over $2 \sigma$ level, and one of these eight peaks, which is about days 96 101 , is near $2 \sigma$ level. The existence of the meteorite streams was implied by these peaks. Especially, the peaks occurring at the days of 41, 96, and 166 appear that a meteorite stream would be passed by Earth orbit.

\section{COMPARISON WITH METEORS AND FIREBALLS}

To appear the computational results of meteor and fireball are required before the meteorite streams were analyzed. There have 208791 records of meteors in the range 2007 2015 from the SonotaCo database (Japan, http://sonotaco. jp/doc/SNM), which reduced from charge-coupled devices (CCDs) of the SonotaCo Network Members in Japan. According to the above database, their bar chart of the annual rates is plotted in Fig. 2a. Then, the database from the National Aeronautics and Space Administration (NASA, http:// cneos.jpl.nasa.gov/fireballs), 388 records of the global fireball that provides a chronological data summary of fireball events provided by U.S. Government sensors in the period of 2005 - 2015 are aggregated. In Fig. 2b the bar chart of the annual rates of fireballs is shown. Figures $2 a$ and $b$ show that the trends in the quantity of meteors and fireballs are similar from 2007 to 2014, and the presentations of amounts between meteors and fireballs are similar.

In Fig. 3a the bar chart of meteors with 1-day bins every year are plotted in black curves and the date with red round

(a)

Events per year



(b)

meteorite

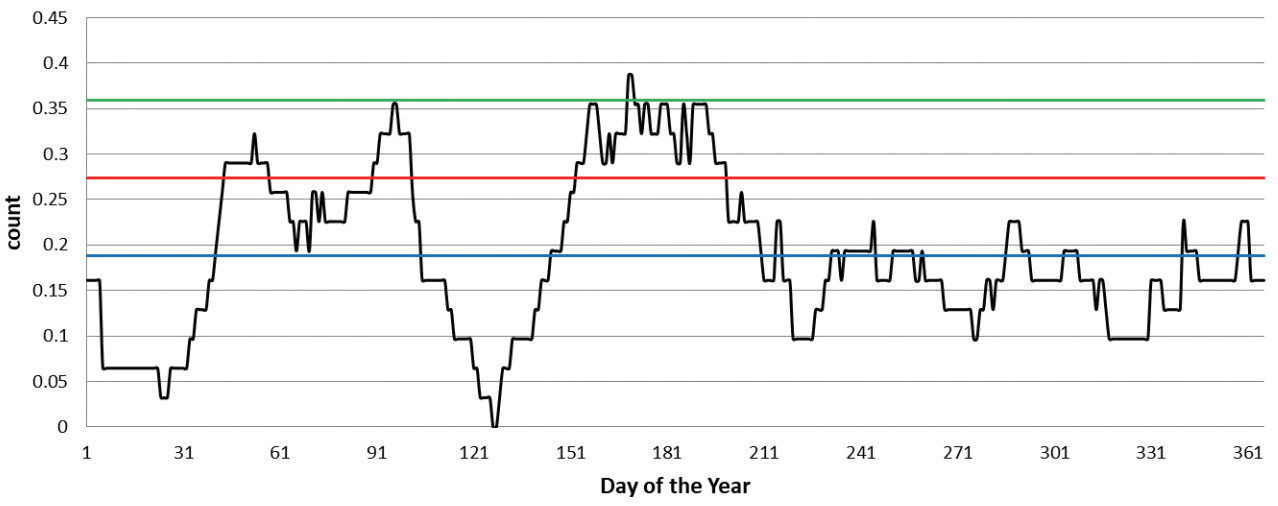

Fig. 1. (a) The bar chart for the annual rates of meteorites. (b) The graph of meteorites with their moving average. The blue line is the average daily occurrence frequency, and the red and green lines are $1 \sigma$ and $2 \sigma$ level. 
(a)

SonotaCo

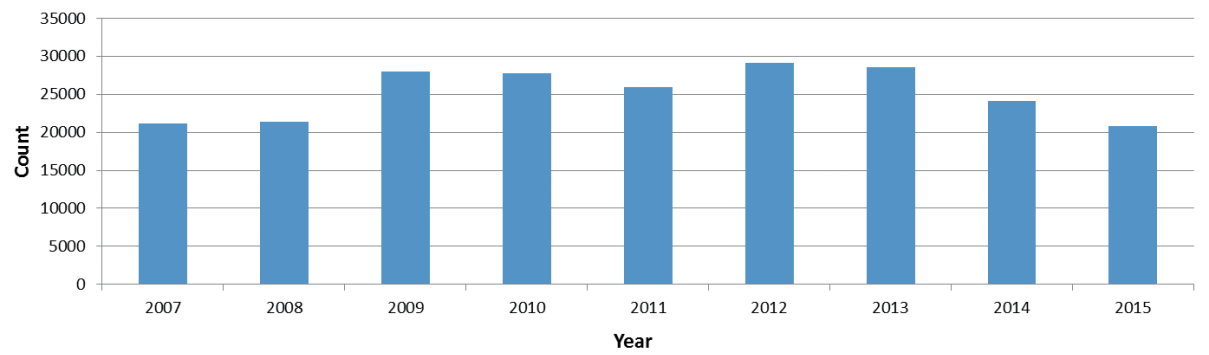

(b)

NASA



Fig. 2. (a) The bar chart for the annual rates of meteors. (b) The bar chart for the annual rates of fireballs.

(a)

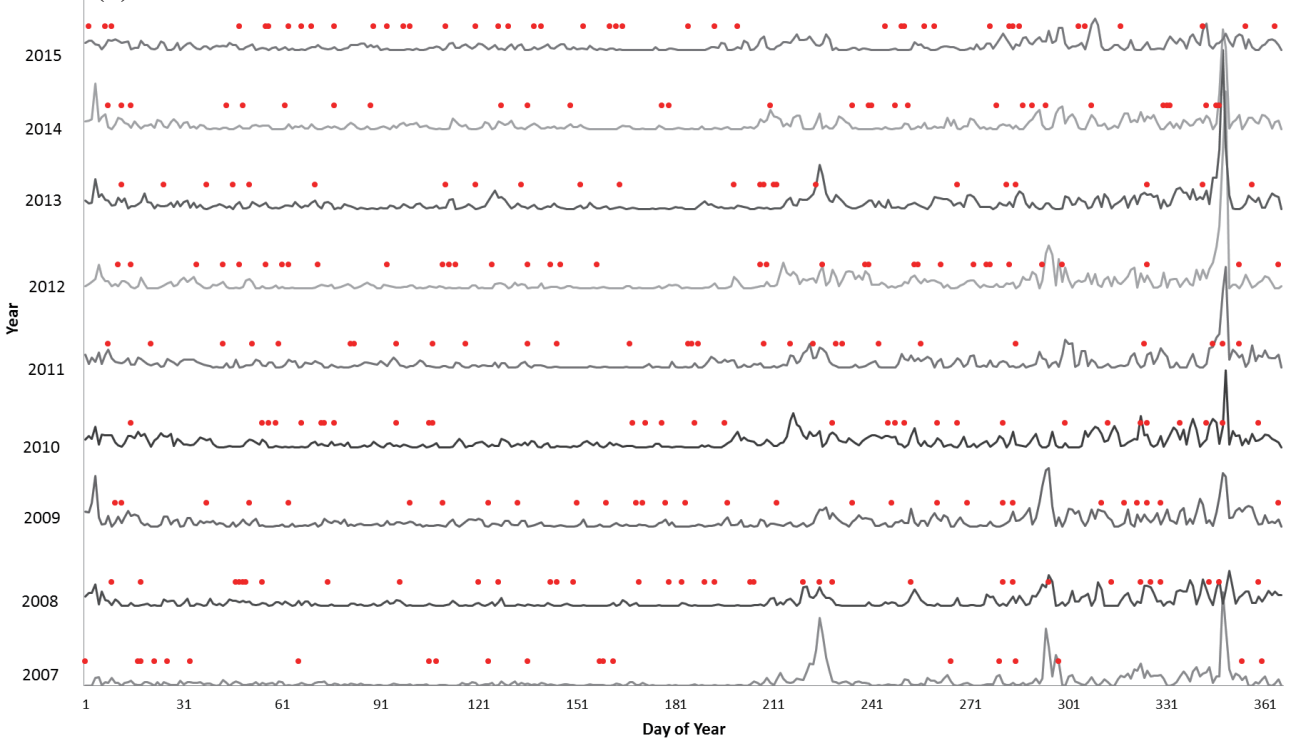

(b)

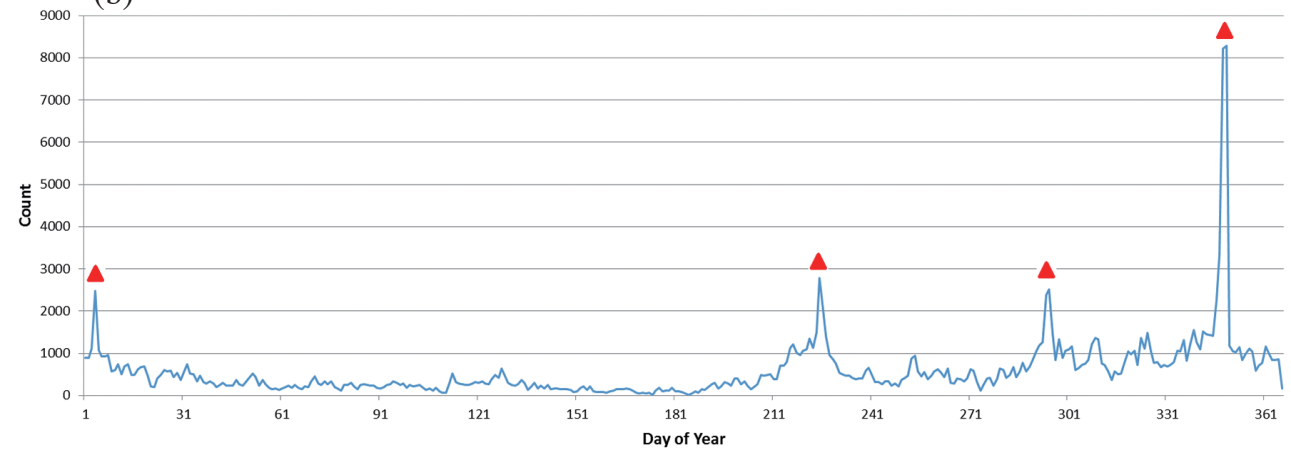

Fig. 3. (a) The bar chart of meteors with 1-day bins every year and the red round dot as fireball occurred. (b) The graph of meteors with 1-day bins . The red triangles are Quadrantids (0010 QUA), Perseides (007 PER), Draconids (009 DRA), and Geminids (004 GEM) sequentially. 
dot as fireball occurred. Here it showed that the fireball that occurred does not overlap the meteor shower. These four main peaks, in Fig. 3b, that are marked by red triangle, are Quadrantids (0010 QUA), Perseides (007 PER), Draconids (009 DRA), and Geminids (004 GEM) sequentially. According to Fig. 3b, there is a window from day 31 st to 181 th in a year. This result is consistent with the article of Campbell-Brown (2007). For the reason the date that occurred between the fireballs and meteors, the source of fireballs is different from the meteors. The bar chart of fireballs with their moving average (orange line) is displayed in Fig. 4a, and the purple line is the average daily occurrence frequency in Fig. $4 b$. Then, the red and green lines are $1 \sigma$ and $2 \sigma$ levels. So, there are nine peaks over $1 \sigma$ level. One of these nine peaks, which are about 63 days, is over $2 \sigma$ level. Those peaks in Fig. $4 \mathrm{~b}$ also mean the existence of a fireball stream, but this is not the focus of this article.

As a result of the peaks of the moving average of meteor in Fig. 4b denoting the existence of the meteor streams, the peaks of the moving average of meteorites in Fig. 1b will appear the existence of meteorite streams. However, the peaks over $1 \sigma$ level emerge from days 41 - 200 for meteorites, and from days 210 - 365 for meteors. The peaks of the moving average of meteorites are different from the moving average of meteors. The peaks of the moving average of meteorites overlap with fireballs (Fig. 4a). Therefore, this implies that the source of meteorite streams similar to fireball streams, but not of the familiar meteor streams.

\section{CONCLUSION}

Besides Chinese historical records, modern scientists will explore meteorites also (Levin and Simonenko 1969). Therefore, some researchers raise the question of whether "meteorite streams" exist (Oberst and Nakamura 1987; Pauls and Gladman 2005; Jones and Williams 2008). In summary, according to the peaks of moving average of meteorite events in Fig. 1b, the appearance of meteorite stream could be found in this article, and these peaks over $1 \sigma$ level emerge from February to July. On the other hand, the peaks of the moving average of meteors emerge from August to January and a window of the moving average of meteors from February to July. This window of the moving average of meteors can be considered as another evidence of the appearance of a meteorite stream. The model of a meteorite stream is shown in Fig. 5, and this meteorite stream could result in the window of the moving average of meteors in purifying meteor streams.

Unlike most of the existing researches, the orbital parameters of meteorite streams are not found, but some recent events support results of the current study. Chelyabinsk meteorite occurred on 15 February 2013 (Popova et al. 2013) and Che et al. (2016) observed the associated meteorite in Korea. They strongly suggested that the first range of peak in Fig. $1 \mathrm{~b}$ might correspond to a meteorite stream. Nevertheless, the source of meteorites would be the bigger size meteoroids which are unlikely to be possible coming from the fragments of comets or asteroids. It will be an open question as to the origin of the meteorite streams if they exist.

Acknowledgements The authors wish to thank the reviewers and editor for their useful comments and suggestions, which significantly improve the paper presentation. Also thanks Miss Pei-Ying Wu for organizing some tables and figures. This study is supported by the Taiwan Ministry of Science and Technology grant MOST 105-2119-M-143002 and NOST 107-2914-I-143-002-A1.

\section{REFERENCES}

Arny, T. and S. Schneider, 2014: Explorations: Introduction to Astronomy, 7th Edition, McGraw-Hill Education, $592 \mathrm{pp}$.

Asher, D. J., 1999: The Leonid meteor storms of 1833 and 1966. Mon. Not. Roy. Astron. Soc., 307, 919-924, doi: 10.1046/j.1365-8711.1999.02698.x. [Link]

Astapovič, I. S. and A. K. Terenteva, 1968: Fireball radiants of the 1st-15th centuries. In: Kresak, L. and P. M. Millman (Eds.), Physics and Dynamics of Meteors, Symposium no. 33, International Astronomical Union, Dordrecht, D. Reidel, 308-319.

Baggaley, W. J., 1977: Mass distribution of massive meteoroids determined by occurrence of brilliant fireballs. Nature, 266, 608-609, doi: 10.1038/266608a0. [Link]

Beech, M., 1986: The Draconid meteoroids. Astron. J., 91, 159-162, doi: 10.1086/113995. [Link]

Beech, M., 2002: The human factor in gathering meteorite falls. Meteorite Magazine, 8, 1-4.

Beech, M., 2006: Meteors and Meteorites: Origins and Observations, Crowood Press, 157 pp.

Brown, P. and J. Jones, 1993: Evolution of the Leonid meteor stream. In: Stohl, J. and I. P. Williams (Eds.), Meteoroids and Their Parent Bodies, Proceedings of the International Astronomical Symposium, Bratislava: Astronomical Institute, Slovak Academy of Sciences, Smolenice, Slovakia, 57-60.

Brown, P. and J. Jones, 1998: Simulation of the formation and evolution of the Perseid meteoroid stream. Icarus, 133, 36-68, doi: 10.1006/icar.1998.5920. [Link]

Brown, P. G., 1999: Evolution of two periodic meteoroid streams: The Perseids and Leonids. Ph.D. Thesis, Faculty of Graduate Studies, the University of Western Ontario (Canada), London, $286 \mathrm{pp}$.

Campbell-Brown, M., 2007: The meteoroid environment: Shower and sporadic meteors. In: Krueger, H. and A. Graps (Eds.), Dust in Planetary Systems, ESA SP-643, European Space Agency, Noordwijk, 11-21.

Che, I.-Y., G. Kim, and H.-I. Lee, 2016: Seismic and 
(a)

\section{fireball}

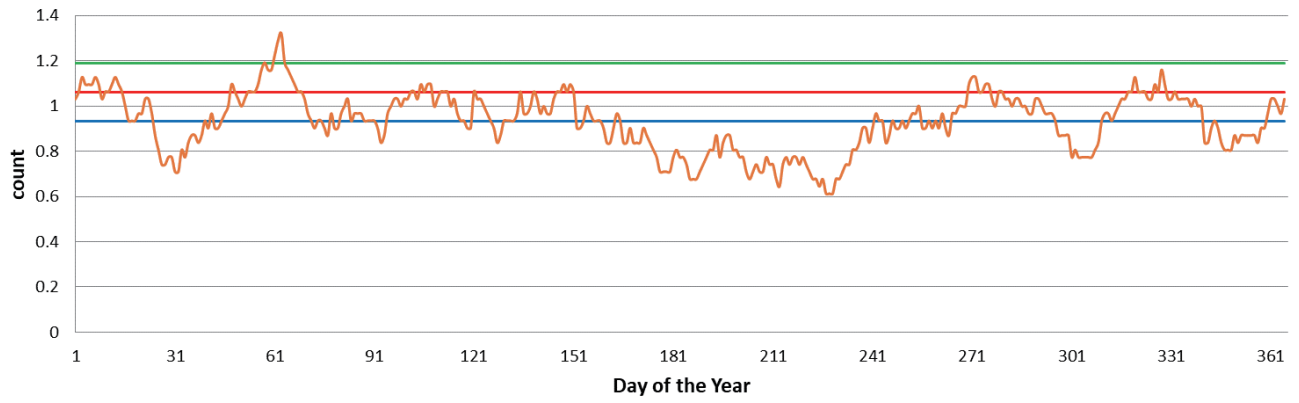

(b)

meteor



Fig. 4. (a) The graph of fireballs with their moving average. The blue line is the average daily occurrence frequency, and the red and green lines are $1 \sigma$ and $2 \sigma$ level. (b) The graph of meteors with their moving average. The blue line is the average daily occurrence frequency, and the red and green lines are $1 \sigma$ and $2 \sigma$ level.

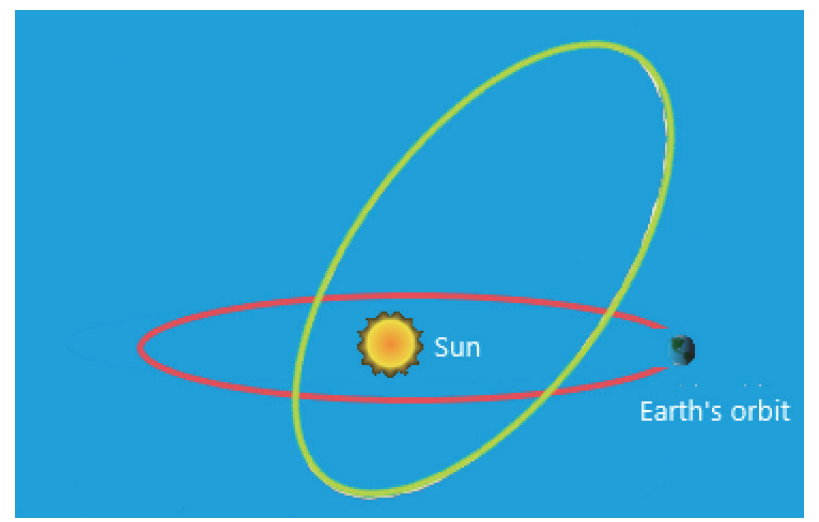

Fig. 5. The model of a meteorite stream. The red circle is Earth's orbit, and the green circle is the orbit of meteorite stream. Commonly the orbit of meteorite stream would be passed twice by Earth. 
infrasonic analysis of the 9 March 2014 fireball in South Korea. Geosci. J., 20, 209-220, doi: 10.1007/ s12303-015-0034-1. [Link]

Davies, J. C. and W. Turski, 1961: The formation of the Giacobinid meteor stream. Mon. Not. Roy. Astron. Soc., 123, 459-470, doi: 10.1093/mnras/123.5.459. [Link]

Davies, J. G. and A. C. B. Lovell, 1955: The Giacobinid meteor stream. Mon. Not. Roy. Astron. Soc., 115, 23-31, doi: 10.1093/mnras/115.1.23. [Link]

Denning, W. F., 1912: The real paths of 429 fireballs and shooting stars observed in the British Isles during the 15 years 1897 to 1911 inclusive. Mon. Not. Roy. Astron. Soc., 72, 423-451, doi: 10.1093/mnras/72.5.423a. [Link]

Di Martino, M. and A. Cellino, 2004: Physical properties of comets and asteroids inferred from fireball observations. In: Belton, M. J. S., T. H. Morgan, N. H. Samarasinha, and D. K. Yeomans (Eds.), Mitigation of Hazardous Comets and Asteroids, Cambridge University Press, Cambridge, 153-166.

Fox, K., I. P. Williams, and D. W. Hughes, 1982: The evolution of the orbit of the Geminid meteor stream. Mon. Not. Roy. Astron. Soc., 200, 313-324, doi: 10.1093/mn$\mathrm{ras} / 200.2 .313$. [Link]

Gavajdová, M., 1995: Search for associations between fireball streams and asteriods. Earth Moon Planets, 68, 289-292, doi: 10.1007/BF00671518. [Link]

Hajduk, A., 1970: Structure of the meteor stream associated with comet Halley. Bulletin of the Astronomical Institute of Czechoslovakia, 21, 37-45.

Hughes, D. W., 1988: P/Halley dust characteristics: A comparison between Orionid and Eta Aquarid meteor observations and those from the flyby spacecraft. In: Grewing, M., F. Praderie, and R. Reinhard (Eds.), Exploration of Halley's Comet, Springer, Berlin, Heidelberg, 879-888, doi: 10.1007/978-3-642-82971-0_149. [Link]

Hughes, D. W. and N. McBride, 1989: The mass of meteoroid streams. Mon. Not. Roy. Astron. Soc., 240, 73-79, doi: 10.1093/mnras/240.1.73. [Link]

Jones, D. C. and I. P. Williams, 2008: High inclination meteorite streams can exist. Earth Moon Planets, 102, 3546, doi: 10.1007/s11038-007-9163-5. [Link]

Jones, J., 1986: The effect of gravitational perturbations on the evolution of the Taurid meteor stream complex. Mon. Not. Roy. Astron. Soc., 221, 257-267, doi: 10.1093/mnras/221.2.257. [Link]

Jopek, T. J. and I. P. Williams, 2013: Stream and sporadic meteoroids associated with near-Earth objects. Mon. Not. Roy. Astron. Soc., 430, 2377-2389, doi: 10.1093/ mnras/stt057. [Link]

Levin, B. J. and A. N. Simonenko, 1969: Meteorite radiants and orbits. In: Millman, P. M. (Ed.), Meteorite Research, Astrophysics and Space Science Library (A
Series of Books on the Recent Developments of Space Science and of General Geophysics and Astrophysics Published in Connection with the Journal Space Science Reviews), Vol. 12, Springer, Dordrecht, 552-558, doi: 10.1007/978-94-010-3411-1_46. [Link]

Lindblad, B. A. and V. Porubčan, 1994: The activity and orbit of the Perseid meteor stream. Planet. Space Sci., 42, 117-122, doi: 10.1016/0032-0633(94)90020-5. [Link]

McIntosh, B. A., 1990: Comet P/Machholz and the Quadrantid meteor stream. Icarus, 86, 299-304, doi: 10.1016/0019-1035(90)90219-Y. [Link]

McIntosh, B. A. and A. Hajduk, 1983: Comet Halley meteor stream: A new model. Mon. Not. Roy. Astron. Soc., 205, 931-943, doi: 10.1093/mnras/205.4.931. [Link]

McNaught, R. H. and D. J. Asher, 1999: Leonid dust trails and meteor storms. WGN, Journal of the International Meteor Organization, 27, 85-102.

Oberst, J. and Y. Nakamura, 1987: Lunar seismic impact clusters - Evidence for the presence of "meteorite streams". LPSC, XVIII, 736.

Pauls, A. and B. Gladman, 2005: Decoherence time scales for "meteoroid streams". Meteorit. Planet. Sci., 40, 1241-1256, doi: 10.1111/j.1945-5100.2005.tb00186.x. [Link]

Plavec, M., 1950: The Geminid meteor shower. Nature, 165, 362-363, doi: 10.1038/165362b0. [Link]

Popova, O. P., P. Jenniskens, V. Emel'yanenko, A. Kartashova, E. Biryukov, S. Khaibrakhmanov, V. Shuvalov, Y. Rybnov, A. Dudorov, V. I. Grokhovsky, D. D. Badyukov, Q.-Z. Yin, P. S. Gural, J. Albers, M. Granvik, L. G. Evers, J. Kuiper, V. Kharlamov, A. Solovyov, Y. S. Rusakov, S. Korotkiy, I. Serdyuk, A. V. Korochantsev, M. Y. Larionov, D. Glazachev, A. E. Mayer, G. Gisler, S. V. Gladkovsky, J. Wimpenny, M. E. Sanborn, A. Yamakawa, K. L. Verosub, D. J. Rowland, S. Roeske, N. W. Botto, J. M. Friedrich, M. E. Zolensky, L. Le, D. Ross, K. Ziegler, T. Nakamura, I. Ahn, J. I. Lee, Q. Zhou, X.-H. Li, Q.-L. Li, Y. Liu, G.-Q. Tang, T. Hiroi, D. Sears, I. A. Weinstein, A. S. Vokhmintsev, A. V. Ishchenko, P. Schmitt-Kopplin, N. Hertkorn, K. Nagao, M. K. Haba, M. Komatsu, and T. Mikouchi, 2013: Chelyabinsk Airburst, Damage Assessment, Meteorite Recovery, and Characterization. Science, 342, 1069-1073, doi: 10.1126/science.1242642. [Link]

Porubčan, V. and M. Gavajdová, 1994: A search for fireball streams among photographic meteors. Planet. Space Sci., 42, 151-155, doi: 10.1016/0032-0633(94)900264. [Link]

Porubčan, V., I. P. Williams, and L. Kornoš, 2004: Associations between asteroids and meteoroid streams. Earth Moon Planets, 95, 697-712, doi: 10.1007/s11038-0052243-5. [Link]

Song, L., 1976: Yuan Shi, Zhonghua Shuju, Beijing. (in Chinese) 
Southworth, R. B. and G. S. Hawkins, 1963: Statistics of meteor streams. Smithsonian Contributions to Astrophysics, 7, 261-285.

Spurný, P., J. Oberst, and D. Heinlein, 2003: Photographic observations of Neuschwanstein, a second meteorite from the orbit of the Príbram chondrite. Nature, 423, 151-153, doi: 10.1038/nature01592. [Link]

Steel, D. I., D. J. Asher, and S. V. M. Clube, 1991: The structure and evolution of the Taurid complex. Mon. Not. Roy. Astron. Soc., 251, 632-648, doi: 10.1093/mn$\mathrm{ras} / 251.4 .632$. [Link]

Terentjeva, A. K., 1990: Fireball streams. In: Lagerkvist, C. I., H. Rickman, and B. A. Lindblad (Eds.), Asteroids, Comets, Meteors III, Uppsala University, Uppsala, 579-584.

Terentjeva, A. K. and S. I. Barabanov, 2002: Family of Minor Bodies Connected with the Prřibram Meteorite. Solar System Research, 36, 431-439, doi: 10.1023/A:1020419606410. [Link]

TuoTuo, 1977: Song Shi, Zhonghua Shuju, Beijing, 14415 pp. (in Chinese)

Williams, I. P. and Z. Wu, 1993: The Geminid meteor stream and asteroid 3200 Phaethon. Mon. Not. Roy. Astron.
Soc., 262, 231-248, doi: 10.1093/mnras/262.1.231. [Link]

Williams, I. P., C. D. Murray, and D. W. Hughes, 1979: The long-term orbital evolution of the Quadrantid meteor stream. Mon. Not. Roy. Astron. Soc., 189, 483-492, doi: 10.1093/mnras/189.3.483. [Link]

Wold, H., 1949: A large-sample test for moving averages. J. R. Stat. Soc. Series B, 11, 297-305, doi: 10.1111/ j.2517-6161.1949.tb00036.x. [Link]

Wu, Z. and I. P. Williams, 1995: P/Giacobini-Zinner and the Draconid meteor shower. Planet. Space Sci., 43, 723-731, doi: 10.1016/0032-0633(94)00127-D. [Link]

Yeomans, D. K., 1981: Comet Tempel-Tuttle and the Leonid meteors. Icarus, 47, 492-499, doi: 10.1016/00191035(81)90198-6. [Link]

Zamora, S., F. Ocaña, A. S. de Miguel, and M. Mole, 2015: On the frequency of the superfireballs: More than 150 years of reports. In: Rault, J.-L. and P. Roggemans (Eds.), Proceedings of the International Meteor Conference, Mistelbach, Austria, International Meteor Organization, 187-191.

Zhang, T.-Y., 1974: Ming Shi, Zhonghua Shuju, Beijing. (in Chinese) 